\title{
Territórios Camponeses e o Fechamento das Escolas do Campo: uma análise sobre a escola popular Eduardo Galeano, em Campo do Meio - MG
}

\author{
Peasant Territories and the Closure of Rural Schools: an analysis of a popular school \\ Eduardo Galeano, Campo do Meio - MG
}

\begin{abstract}
Territorios Campesinos y Cierre de Escuelas Rurales: un análisis de la escuela popular Eduardo Galeano, en Campo do Meio - MG
\end{abstract}

\author{
Leonardo Lencioni Mattos Santos ${ }^{1}$ \\ https://orcid.org/0000-0001-8597-0847 \\ Estevan Leopoldo de Freitas Coca ${ }^{2}$ \\ https://orcid.org/0000-0001-9424-9699
}

\begin{abstract}
RESUMO: O fechamento de escolas do campo representa uma das consequências mais drásticas do avanço e rapina dos territórios camponeses pelo agronegócio no Brasil. Sabendo disso, nesse trabalho damos ênfase a algumas das disputas territoriais nas quais a educação do/no Campo está inserida no contexto histórico atual. Para isso, foi analisada a relação entre educação e luta pela/na terra do Movimento dos Trabalhadores Rurais Sem Terra (MST) a partir do fechamento da escola popular Eduardo Galeano, localizada no conjunto de acampamentos Quilombo Campo Grande, no município de Campo do Meio - MG. Realizou-se o levantamento do processo de fechamento de escolas rurais em todo o país entre os anos de 2010 e 2019, além de trabalhos de campo e entrevistas no Quilombo Campo Grande. Com isso, se propõe uma leitura pautando o território enquanto categoria chave para a compreensão dos projetos de Educação do Campo e da conflitualidade atual do campo brasileiro. Ademais, destacamos como os processos educacionais em áreas de reforma agrária podem ser fatores de fortalecimento da luta pela/na terra e para a conformação das territorialidades camponesas.
\end{abstract}

PALAVRAS-CHAVE: Território. Educação do Campo. Fechamento de escolas rurais. Campesinato.

ABSTRACT: The closure of rural schools represents one of the most drastic consequences of the way in which agribusiness advances over and preys upon peasant territories in Brazil. In this paper we emphasize some of the territorial disputes in which Education for and by the countryside is present in

\footnotetext{
${ }^{1}$ Mestrando em Geografia pela Universidade Federal de Alfenas, Instituto de Ciências da Natureza. E-mail: leonardo.lencioni@sou.unifal-mg.edu.br.

${ }^{2}$ Doutorado pela Universidade Estadual Paulista (UNESP), docente da Universidade Federal de Alfenas (UnifalMG). E-mail: estevan.coca@unifal-mg.edu.br.
} 
the current historical context. For this, the relationship between education and the the Landless Rural Workers Movement's (MST) struggle on/for the land was analyzed after the closure of the popular school Eduardo Galeano, located in the collection of occupied sites in Quilombo Campo Grande, in the municipality of Campo do Meio - MG. The process of closing rural schools across the country between 2010 and 2019 was mapped, in addition to fieldwork and interviews in Quilombo Campo Grande. With this, a reading is proposed, guiding the territory as a key category for the understanding of Education for and by the Countryside projects and the current conflict in the Brazilian countryside. In addition, we highlight how educational processes in areas of agrarian reform can be factors in strengthening the struggle on/for land and in shaping peasant territorialities.

KEYWORDS: Territory. Countryside education. Closure of Rural Schools. Peasantry.

RESUMEN: El cierre de las escuelas del campo representa una de las consecuencias más drásticas del avance y expoliación de los territorios campesinos por el agronegocio en el Brasil. Sabiéndolo, en este trabajo damos énfasis a algunos de los territorios en los cuales la educación de el/ en el campo se inserta en el contexto histórico actual. Para eso, fue examinada la relación entre educación y la lucha por la/en la tierra del Movimento dos Trabalhadores Sem Terra (MST) a partir del cierre de la escuela popular Eduardo Galeano, ubicada en el conjunto de campamentos del Quilombo Campo Grande, en el municipio de Campo do Meio - MG. El proceso de cierre de escuelas rurales en todo el país se llevó a cabo entre 2010 y 2019, y también se aplicaron trabajos de campo y entrevistas en Quilombo Campo Grande. Así, se propone una lectura pensando el territorio conforme una categoría clave para la comprensión de los proyectos de Educación del Campo y de la conflictividad actual en los campos brasileños. Además, señalamos como los procesos educacionales en áreas de reforma agraria sean posibles como factores de fortalecimiento de la lucha por la/en la tierra y para la conformación de las territorialidades del campesinado.

PALABRAS-CLAVE: Territorio. Educación del Campo. Cierre de escuelas rurales. Campesinado.

\section{INTRODUÇÃO}

O quadro de abandono do Estado com a educação no meio rural brasileiro é histórico, exemplo disso é que a criação e a manutenção de escolas no campo por muito tempo dependeram dos "favores" prestados por fazendeiros aos camponeses e trabalhadores rurais (MOREIRA, 2018). Estas escolas geralmente encontravam-se dentro de fazendas, muitas vezes em cômodos disponibilizados pelos fazendeiros, que indicavam como professoras alguém de sua família, como filhas ou noras.

A partir da década de 1990, movimentos socioterritoriais e setores da academia passaram a lutar por metodologias e projetos educacionais pensados para e por camponeses (as). Os debates apontavam para a necessidade de se levar em consideração os territórios, os modos de vida, o trabalho e a cultura camponesa enquanto fatores fundamentais para o processo de ensino-aprendizagem, formando-se os princípios da Educação do Campo (SANTOS; SOUZA, 2007). 
Apesar dos recentes avanços em termos de políticas públicas, a educação no meio rural segue sendo alvo de ataques dos mais diversos, seja daqueles conduzidos por setores do agronegócio, seja dos conduzidos pelo próprio Estado (CAMACHO, 2014).

Com base nesse contexto, no presente trabalho a Educação do/no Campo é entendida como um território em disputa, tanto imaterial quanto materialmente. Os contornos da Questão Agrária (QA) atual fazem com que essa disputa seja caracterizada pelo grande número de estabelecimentos escolares fechados, pela influência do agronegócio na produção de materiais didáticos e cursos para professores da rede pública, pelo subfinanciamento e até mesmo pela completa extinção de políticas públicas voltadas à educação no campo (CAMACHO, 2014; MOLINA, 2015; SILVA, 2016).

Para problematizar como isso repercute nas disputas territoriais entre o campesinato e o agronegócio, trazemos uma discussão sobre o processo de fechamento e destruição da escola popular Eduardo Galeano, localizada no conjunto de acampamento Quilombo Campo Grande, em Campo do Meio - MG. Esses acampamentos compõem um dos principais e mais duradouros conflitos pela posse da terra no Brasil, envolvendo o Movimento do Trabalhadores Sem-Terra (MST) e a Usina Ariadnópolis.

Demonstramos que a luta pela Educação do/no Campo está diretamente vinculada à luta pela manutenção e/ou conquista de territórios por parte do campesinato. Da mesma forma, a destruição e o fechamento de escolas no campo brasileiro aparenta ser uma estratégia de setores conservadores para impedir o avanço e a consolidação desses territórios e seus modos de vida. Neste sentido, a educação é uma das dimensões fundamentais para a compreensão das disputas territoriais nas quais o campesinato brasileiro está envolvido.

Destacamos que o conceito de Educação no campo é aqui entendido enquanto qualquer processo educacional que ocorra no meio rural. Já a Educação do Campo é "[...] um fenômeno da realidade brasileira atual, protagonizado pelos trabalhadores do campo e suas organizações, que visa incidir sobre a política de educação desde os interesses sociais das comunidades camponesa" (CALDART; PEREIRA; FRIGOTTO, 2012, p. 259).

\section{METODOLOGIA}

Este trabalho é fruto de uma pesquisa desenvolvida junto ao departamento de Geografia da Universidade Federal de Alfenas (UNIFAL-MG) entre os anos de 2019 e 2020. A necessidade de analisar a realidade educacional do conjunto de acampamentos e assentamentos de Campo do Meio se iniciou com as demandas apresentadas pelo setor de educação do MST durante diversas visitas realizadas pelos pesquisadores à escola popular Eduardo Galeano. Em maio de 2019, o setor de educação do MST em Campo do Meio 
informou sobre o processo de fechamento da escola - até então muito recente - e prospectou a possibilidade de realização de uma pesquisa sobre a escola.

Assim, essa pesquisa baseou-se em uma metodologia participativa (SANTOS, 2005; STRECK, 2016), visto que possui como propósito a busca pelo desenvolvimento de um conhecimento que esteja inserido em uma perspectiva de emancipação dos sujeitos e de transformação da realidade. O sentido aqui empregado de metodologia participativa abarcou o desenvolvimento de procedimentos que permitissem aos atores sociais serem ouvidos e participarem de maneira ativa na construção do conhecimento científico (SANTOS, 2005). Assim, pautamos que a ideia de imparcialidade científica é ilusória ao entendermos que a escolha dos métodos, metodologias e até mesmo dos objetos de análise das pesquisas são totalmente permeadas pelas intencionalidades e ideologias dos(as) pesquisadores(as) (CAMPOS, 2012; SANTOS, 2005).

A pesquisa começou com uma revisão de literatura. Após esse momento buscamos dados secundários capazes de demonstrar a dinâmica de fechamento de escolas rurais no país. Desta forma, foram utilizados os dados provenientes do censo escolar dos anos de 2010 e 2019, disponíveis no sítio eletrônico do Instituto Nacional de Estudos e Pesquisas Educacionais Anísio Teixeira (INEP).

Ademais, foram realizadas entrevistas de caráter semiestruturado com três membros(as) do setor de educação do MST de Campo do Meio, sendo um professor da escola em questão, bem como com três alunos(as) da Educação de Jovens e Adultos (EJA) que estudaram na escola. A utilização das entrevistas como metodologia de pesquisa parte do princípio de que, por meio delas, é possível se extrair informações capazes de elucidar questões importantes. Como as perguntas aplicadas eram semiabertas, optou-se por classificar as respostas de acordo com grupos de afinidade (COLOGNESE; MÉLO, 1998).

Após a transcrição das entrevistas foram delimitadas quatro categorias que permitiram a leitura e escolha dos dados relevantes para a pesquisa; desta forma, os dados obtidos com as entrevistas foram adicionados a um quadro no software Microsoft Excel e divididos nas seguintes categorias: i) Processo de formação da escola; ii) Problemas enfrentados pelos alunos para estudarem no campo e na cidade; iii) Processo de fechamento da escola e iv) Características do processo educacional e seus impactos nas territorialidades camponesas.

\section{TERRITÓRIO E EDUCAÇÃO DO/NO CAMPO}

Para discutir a relação entre a Educação no/do Campo e as disputas territoriais, partimos do princípio de que o espaço é anterior ao território (RAFFESTIN, 1993), ou seja, o 
território é resultante do espaço geográfico, sendo construído a partir das relações sociais que ocorrem durante o processo de produção do espaço. Deste modo, ao se apropriarem do espaço os indivíduos se territorializam, "O território, nessa perspectiva, é um espaço onde se projetou um trabalho, seja energia e informação, e que, por consequência, revela relações marcadas pelo poder" (RAFFESTIN, 1993, p. 144).

Logo, compreende-se que os territórios por si só não são capazes de definir os sujeitos, do mesmo modo que não é possível se definir os sujeitos ao se desconsiderar os territórios onde vivem/atuam (FERNANDES, 2009). Não é possível, também, compreender um dado território sem conhecer os sujeitos, empresas, instituições e movimentos socioterritoriais que estão por trás de sua produção. Os territórios produzem e são produzidos pelas relações sociais (relações de poder) que nele ocorrem e que o modificam, sendo também moldados pelas diversas temporalidades oriundas daqueles que o produzem (SOBREIRO FILHO, 2016).

Ainda é recorrente na Geografia a utilização do conceito de território apenas enquanto espaço de governança, ou seja, em seu vínculo direto com o conceito de Estado-nação (GOTTMANN, 2012). Em contrapartida, alguns geógrafos vêm buscando desenvolver conceitualmente uma leitura de território que seja mais ampla e que leve em conta os diversos territórios produzidos por grupos historicamente invisibilizados (FERNANDES, 2008a; SOBREIRO FILHO, 2020).

Observa-se que, ao analisar o território somente enquanto espaço de governança, podemos ocultar as conflitualidades e as resistências que ocorrem entre os diversos tipos de territórios, negligenciando a multiescalaridade. Ademais, o território também deve ser compreendido por meio do princípio da totalidade, cada território precisa ser analisado como um todo, considerando esse todo como uma parte da realidade e do espaço geográfico (FERNANDES, 2008a). A diferenciação ocorre por meio das relações sociais que constroem os territórios e se apresentam por meio da multidimensionalidade, o que significa a necessidade de se analisar um território a partir das dimensões (dimensão política, educacional, cultural, econômica e ambiental) que o compõem (FERNANDES, 2008a; 2009).

É necessário pautar a análise dos diversos usos dados ao território de acordo com os sujeitos que o constroem. A multiterritorialidade é, portanto, a propriedade que trata a diversidade de territorialidades. Essas territorialidades se originam dos diferentes usos e das diferentes relações sociais que compõem, criam e são criadas em determinado território. Como se verá mais adiante, os distintos usos e relações que as pessoas desenvolvem em seus territórios (e aqui os projetos de desenvolvimento territorial também se inserem) são parte do processo de conflitualidade existente no campo. 
Para os indígenas a terra/território é parte de sua ancestralidade e cultura (HAESBAERT, 2020), para o campesinato ele é espaço de vida, de reprodução de seus valores (CALDART; PEREIRA; FRIGOTTO, 2012), enquanto para a agricultura capitalista (agronegócio) o campo é visto somente como espaço produtivo (FERNANDES, 2008b). Isso é observável, também, ao analisar os modelos de educação que se dão a partir dos diferentes paradigmas. As intencionalidades daqueles que produzem estes modelos são parte fundamental para o entendimento dos territórios e territorialidades.

Assim, torna-se importante compreender as intencionalidades dos sujeitos que vivem e/ou que elaboram (no caso dos territórios imateriais) os territórios. A intencionalidade seria então a visão de mundo ou os paradigmas que guiam os sujeitos na produção de suas vidas e de seus territórios. Ou seja, são os elementos subjetivos empregados na criação e na consolidação de seus espaços de vida/produção (FERNANDES, 2008a). Diferentes intencionalidades (agronegócio, campesinato e povos tradicionais não possuem as mesmas formas de ver e agir no mundo) geram divergências e, em uma sociedade de classes, conflitualidade.

A conflitualidade é o processo histórico de enfrentamento que busca a permanência ou a superação de classes sociais, espaços e territórios observável por meio das contradições estruturais do modo capitalista de produção (FERNANDES, 2009; SOBREIRO FILHO, 2016). A partir dessas contrições são produzidos espaços e territórios heterogêneos, o que gera a conflitualidade.

Portanto, a conflitualidade é entendida aqui enquanto um processo em que o conflito é apenas um dos componentes. Seu cerne está nas contradições do sistema de produção capitalista, reside na disputa pelos modelos de desenvolvimento territorial que, na atual conjuntura de políticas neoliberais, acabam por se caracterizar enquanto excludentes para a população camponesa.

Cabe ressaltar que a relação entre os territórios como espaço de governança (Estado) e como propriedades (privadas ou coletivas) ocorre por meio das políticas de desenvolvimento territorial. A determinação da forma de organização dos territórios também é condicionada por quem produz essas políticas (FERNANDES, 2008a). É desta forma que a destruição ou criação de políticas públicas repercute em todas as escalas territoriais. Como na conjuntura política atual os anseios dos movimentos socioterritoriais camponeses não são ouvidos, eles terão menor poder para influenciar na implementação de políticas públicas e de projetos de desenvolvimento territorial que os favoreçam. Com isso, aumentase a capacidade do capital em des(re)territorializar o campesinato, dificultando o acesso à direitos básicos, como a educação. 
Outra consideração importante a se fazer a respeito dos territórios é a relação existente entre os territórios materiais e imateriais. Os territórios materiais são aqueles formados no espaço físico, enquanto os imateriais se realizam através das relações sociais "[...] por meio de pensamentos, conceitos, teorias e ideologias" (FERNANDES, 2008a, p. 282). Ambos se formam de maneira dialética, um não existe sem o outro. São indissociáveis, pois a criação e manutenção do território material é resultado de relações de poder que se sustentam por meio de territórios imateriais, como as políticas públicas, o conhecimento, os modelos educacionais, as teorias e as ideologias.

A importância de se analisar os aspectos imateriais reside em se compreender os diversos tipos de territórios materiais existentes e em se pensar que essas imaterialidades são também determinadas pelas relações de poder (CAMACHO, 2014; FERNANDES, 2008a). Essas relações de poder ora se configuram no sentido de favorecer o território e a territorialidade camponesa, ora enquanto fatores que favorecem a sujeição do campesinato aos ditames do capital. Ou seja, é necessária a existência de um território imaterial enquanto base para que um território material exista, ou seja, disputado.

Com base nessa compreensão, entendemos a Educação do/no Campo enquanto um território imaterial sendo disputado por meio de políticas públicas que a favoreçam ou não e também por meio de ações por parte do agronegócio, como se verá mais adiante. Esse processo vem gerando impactos diretos nos territórios materiais, ou seja, na des-reterritorialização do campesinato.

\section{DISPUTAS TERRITORIAIS E EDUCAÇÃO DO/NO CAMPO}

A Educação do Campo se constitui tanto como um instrumento da luta do campesinato contra a territorialização do agronegócio, quanto como uma prática oriunda desta luta (REIS; SOBREIRO FILHO; RABELO, 2019). Neste sentido, ela pode ser entendida como uma Educação Territorial (CAMACHO, 2014; FERNANDES, 2006), pois se dá a partir da identidade territorial do campesinato.

A Educação do Campo se configura através da relação dialética entre o campesinato e seu território. Desde os finais dos anos de 1980, os movimentos socioterritoriais passaram a lutar pela instituição da Educação do Campo nas áreas de reforma agrária a fim de fazer válida seu direito à educação, educação esta que levasse em consideração os valores e a cultura do campesinato. De acordo com Caldart (2003, p. 61): "[...] quase ao mesmo tempo em que começaram a luta pela terra, os sem-terra do MST também começaram a lutar por escolas e, sobretudo, para cultivar em si mesmo o valor do estudo e do próprio direito de lutar pelo seu acesso a ele [...]". Através dos movimentos socioterritoriais, a Educação do Campo passa a ser construída por meio de dimensões educacionais que extrapolam a 
educação escolar, englobando o conflito, a luta de classes e o trabalho enquanto elementos de seus processos educativos (CALDART, 2015; CAMACHO, 2014; MOLINA, 2015).

A partir dos debates e da pressão política gerada pela sociedade civil e pelos movimentos socioterritoriais em prol do estabelecimento da Educação do Campo diversas políticas públicas educacionais passaram a ser instituídas a partir dos anos 1990 (SANTOS; SOUZA, 2007). Desta forma, por meio das lutas travadas pelos movimentos socioterritoriais camponeses, houve diversas conquistas referentes aos programas de Educação do Campo, com grande destaque ao Programa Nacional de Educação na Reforma Agrária (PRONERA) e ao Programa de Apoio às Licenciaturas em Educação do Campo (PROCAMPO), responsável pela formação de docentes para atuarem em áreas de reforma agrária. Estes programas são práticas concretas que partiram das concepções da Educação do Campo.

Por meio da luta dos movimentos socioterritoriais e dos debates ocorridos na academia, houve a criação de um território imaterial, o Paradigma Originário da Educação do Campo (CAMACHO, 2014, 2019), resultando diretamente na formulação de políticas públicas educacionais adequadas aos camponeses. Sendo assim, através da luta por territórios nas áreas de reforma agrária os movimentos socioterritoriais passaram a lutar também por um modelo de educação, criando um território imaterial denominado de Educação do Campo. A partir das especificidades e necessidades educacionais enfrentadas pelo campesinato, houve a disputa pela criação de políticas públicas educacionais que possibilitassem ou favorecessem a reprodução dos valores e dos territórios camponeses, além de uma melhoria na condição de vida desses sujeitos a partir de seus ideais.

Por outro lado, desde o segundo mandato da ex-presidenta Dilma Roussef as políticas públicas voltadas à educação deixaram de ser orientadas pelas demandas populares e passaram a ser influenciadas por uma perspectiva de cunho neoliberal (TAFFAREL; MUNARIM, 2015). Atualmente verificam-se diversas disputas pelo território imaterial da Educação do Campo, ou seja, pela conformação de sua estrutura ideológica e das políticas públicas educacionais. São exemplos dessas disputas a política de fechamento das escolas do campo com sua nucleação em áreas urbanas, a atuação de empresas do agronegócio na formulação de materiais didáticos, na criação de cursos de capacitação de professores da rede pública de ensino e na implementação de modelos educacionais como o Programa Empreendedorismo do Jovem Rural, financiado pelo Instituto Souza Cruz, no Paraná (CALDART, 2010; CAMACHO, 2014; MOLINA, 2015; SILVA, 2016).

Um dos piores impactos sofridos pela Educação do Campo enquanto política pública se deu por meio do esvaziamento do PRONERA a partir de um decreto do presidente da república Jair Bolsonaro. O decreto $n^{\circ}$ 10.252, de 20 de fevereiro de 2020, alterou a estrutura regimental do Instituto Nacional de Colonização e Reforma Agrária (INCRA) e 
extinguiu a Coordenação-Geral de Educação do Campo e Cidadania, a responsável pela gestão do PRONERA.

Os conflitos por estes territórios imateriais ocorrem justamente pelo fato de o campo estar sendo disputado por modelos de desenvolvimento territorial e educacional que são distintos (CAMACHO, 2014). Para o campesinato a educação é tida como instrumento e produto de sua luta (REIS; SOBREIRO FILHO; RABELO, 2019), capaz de favorecer a reprodução de seu território, de sua diversidade cultural, de sua economia e de sua história política (ARROYO, 1999).

Já para o agronegócio e o Estado ela é vista enquanto possibilidade para se "[...] manter as relações desiguais do capitalismo se perpetuando, como o trabalho escravo e os gastos de dinheiro público para atender as demandas do capital [...]" (CAMACHO, 2014, p. 74). Por detrás disso, vê-se o discurso do agronegócio voltado para a formação de empreendedores rurais e para a "integração" dos agricultores familiares ao mercado. Para compreender a dinâmica do fechamento das escolas do campo, comparamos o número de escolas em atividade nos anos de 2010 e 2019 (Tabela 1).

Analisando os dados é possível verificar que o fechamento das escolas do campo vem ocorrendo de maneira exacerbada em todo o país. Somente entre os anos de 2010 a 2019 houve o encerramento de $\mathbf{2 4 . 1 1 4}$ escolas rurais em todo o território nacional. Apenas Roraima, Mato Grosso do Sul e o Distrito Federal apresentaram aumento no número de estabelecimentos educacionais rurais, mesmo que quase irrisório. A média de estabelecimentos de ensino fechados entre 2010 e 2019, por unidade da federação, no período observado, foi de 893 escolas. Alguns estados merecem destaque negativo por terem ultrapassado em muito essa média, como Bahia, Piauí, Maranhão, Ceará, Pernambuco, Pará e Minas Gerais.

O Nordeste figura enquanto a grande região brasileira com a maior quantidade de estabelecimentos fechados, sendo $\mathbf{1 6 . 2 2 0}$ escolas a menos em 2019, o que representa $67,2 \%$ do total de escolas fechadas no país. Na sequência temos a região Norte, com 2.979 estabelecimentos fechados, ou 12,35\%, seguida pelo Sudeste, com 2.802 estabelecimentos fechados, ou 11,61\%; Sul, com 1.740 estabelecimentos fechados, ou 7,21\%; e CentroOeste, com 302 estabelecimentos fechados, ou 1,25\% das escolas encerradas no país. Apesar da dinâmica de fechamento ser menor no Centro-Oeste esta é também a região com o menor número de escolas rurais no país.

Um| ponto que corrobora nossa análise é que o número de pessoas que residem em áreas rurais se manteve estável entre 2010 e 2015. De acordo com os dados do IBGE (2010, 2015), a população rural brasileira se manteve na faixa de $15 \%$ da população nacional. Portanto, entendemos que se entre 2010 e 2015 não houve diminuição considerável no número de habitantes das zonas rurais brasileiras (na verdade, o número 
aumentou), o processo de fechamento dessas escolas não deve estar ligado diretamente à redução da demanda por educação.

Tabela 1 - Escolas rurais em atividade, por grande região e unidade da federação, nos anos de 2010 e 2019

\begin{tabular}{|c|c|c|c|}
\hline $\begin{array}{l}\text { Grande } \\
\text { Região }\end{array}$ & $\begin{array}{l}\text { Unidades da } \\
\text { Federação }\end{array}$ & $\begin{array}{c}\text { Escolas em } \\
\text { atividade em } \\
2010\end{array}$ & $\begin{array}{l}\text { Escolas em } \\
\text { atividade em } 2019\end{array}$ \\
\hline Norte & Rondônia & 720 & 420 \\
\hline Norte & Acre & 1.328 & 1.125 \\
\hline Norte & Amazonas & 4.033 & 3.596 \\
\hline Norte & Roraima & 508 & 565 \\
\hline Norte & Pará & 8.738 & 6.969 \\
\hline Norte & Amapá & 480 & 460 \\
\hline Norte & Tocantins & 827 & 520 \\
\hline Nordeste & Maranhão & 9.962 & 7.730 \\
\hline Nordeste & Piauí & 4.304 & 2.059 \\
\hline Nordeste & Ceará & 4.659 & 2.642 \\
\hline Nordeste & Rio Grande do Norte & 1.819 & 1.273 \\
\hline Nordeste & Paraíba & 3.478 & 1.930 \\
\hline Nordeste & Pernambuco & 5.268 & 3.269 \\
\hline Nordeste & Alagoas & 1.835 & 1.286 \\
\hline Nordeste & Sergipe & 1.231 & 900 \\
\hline Nordeste & Bahia & 12.875 & 8.122 \\
\hline Sudeste & Minas Gerais & 5.179 & 3.253 \\
\hline Sudeste & Espírito Santo & 1.446 & 1.023 \\
\hline Sudeste & Rio de Janeiro & 1.319 & 1.103 \\
\hline Sudeste & São Paulo & 1.469 & 1.232 \\
\hline Sul & Paraná & 1.688 & 1.262 \\
\hline Sul & Santa Catarina & 1.603 & 1.088 \\
\hline Sul & Rio Grande do Sul & 2.731 & 1.932 \\
\hline Centro-Oeste & Mato Grosso do Sul & 231 & 239 \\
\hline Centro-Oeste & Mato Grosso & 930 & 770 \\
\hline Centro-Oeste & Goiás & 648 & 492 \\
\hline Centro-Oeste & Distrito Federal & 79 & 85 \\
\hline \multicolumn{2}{|r|}{ Total } & 79.388 & 55.345 \\
\hline
\end{tabular}

Fonte: Organizado por Leonardo L. M. Santos de: Instituto Nacional de Estudos e Pesquisas Educacionais Anísio Teixeira $(2011,2020)$.

Ao analisarmos as regiões brasileiras com o maior número de escolas encerradas, percebemos ainda mais essa contradição. Enquanto em 2015 a região Norte contava com $25 \%$ de sua população residindo no campo, o Nordeste do país possuía $26,88 \%$ de sua população no meio rural (IBGE, 2015). Essas são justamente as regiões brasileiras com o maior número de escolas encerradas. 


\section{LUTA PELA/NA TERRA NO MUNICÍPIO DE CAMPO DO MEIO-MG}

De acordo com o Censo Demográfico de 2010, 11.476 pessoas residiam em Campo do Meio, das quais 10.106 habitavam a zona urbana e 1.412 a zona rural (IBGE, 2010). O município apresenta-se como uma exceção à organização territorial da mesorregião, visto sua elevada concentração de terras, representada pela existência de latifúndios, como a exusina Ariadnópolis e a Fazenda Jatobá (VALE et al., 2019). Por meio dos dados do Censo Agropecuário de 2017 (IBGE, 2018) verificou-se que o número de estabelecimentos agropecuários da agricultura familiar representar $77,48 \%$ do total de estabelecimentos de Campo do Meio, mas apenas $36,72 \%$ da área do município está sob a posse da agricultura familiar.

O processo de conflitualidade entre trabalhadores rurais e o agronegócio em Campo do Meio remonta à década de 1990. Em 1995 iniciou-se uma greve articulada pelo Sindicato de Trabalhadores Rurais de Campo do Meio e Região contra a exploração de mão-de-obra pela usina de álcool Ariadnópolis (que se encontrava em processo pré-falimentar). A usina era gerenciada pela Companhia Agropecuária Irmãos Azevedo (CAPIA). Nesse momento os funcionários estavam há quatro meses sem receber seus salários e alguns tantos lutavam para conseguir o recebimento dos demais direitos trabalhistas em débito (LUCAS; VALE, 2014; VALE et al., 2019).

Em novembro de 1996, funcionários da usina que faziam parte da greve e famílias oriundas de outras regiões de Minas Gerais contaram com o apoio do MST e ocuparam uma área próxima à usina. Esta área, chamada de Fazenda Jatobá, encontrava-se em processo de remate para a quitação de suas dívidas. A ocupação contou com cerca de 50 pessoas e em maio de 1997 o Governo Federal adquiriu as terras, indenizando o proprietário e criando o primeiro assentamento do Sul de Minas Gerais: o Primeiro do Sul (LUCAS; VALE; 2014).

A luta pela terra em Campo do Meio se ampliou nos anos seguintes, em 1998 o MST ocupou uma área de cerca de 3.600 hectares pertencente à CAPIA, que então viria a ser o conjunto de acampamentos Quilombo Campo Grande. Atualmente, 11 acampamentos fazem parte de suas áreas. O número de reintegrações de posse ocorridas contra o Quilombo Campo Grande demonstra a histórica conflitualidade entre o campesinato e o latifúndio/agronegócio no município. Nos anos de 1998, 2004, 2005, 2007, 2009 e 2020 foram expedidos mandados judiciais com a finalidade de execução de reintegrações de posse (AMARAL, 2019).

O processo de reforma agrária em Campo do Meio esbarra na lógica da judicialização (STÉDILE; FERNANDES, 1999), ou seja, no uso do judiciário, por parte das elites locais e regionais, para impedir a conquista de terras pelos movimentos socioterritoriais. Parte da 
violência sofrida pelos camponeses no Sul de Minas Gerais não é ocasionada pelo embate direto com os latifundiários, ela é oriunda de instituições estatais, por meio da judicialização da luta pela/na terra e da ação desmedida e desproporcional da Polícia Militar nos processos de reintegração de posse. Porém, isso não significa (muito pelo contrário) que os camponeses do Quilombo Campo Grande não sofram diversas violências por parte de capangas/jagunços ligados aos latifundiários da região, mas sim que o judiciário se constitui enquanto o braço repressivo por excelência destes latifundiários.

\section{A ESCOLA POPULAR EDUARDO GALEANO}

A escola popular Eduardo Galeano localizava-se na zona rural do município de Campo do Meio, tendo como fronteira física a ex-usina Ariadnópolis. A área onde estava inserida é alvo de uma disputa judicial que dura mais de duas décadas pelo controle da terra, sendo este conhecido como o principal conflito fundiário do Sul de Minas Gerais (COCA et al., 2020).

A designação "popular" em seu nome tem origem nos preceitos da educação popular. Esta configura-se como um paradigma teórico originado das lutas populares que visa tanto a construção de saberes, quanto o fortalecimento das organizações sociais (CARRILLO, 2011). O sentido "popular" dessa proposta não reside no fato de que o seu trabalho se dirige a operários, camponeses e classes populares, mas sim que o conteúdo ensinado por ela é organicamente vinculado com a possibilidade de se criar um saber popular (BRANDÃO, 1986).

De acordo com o entrevistado 01, o processo de criação da escola popular Eduardo Galeano partiu de uma ocupação realizada em 2014 em uma área da ex-usina Ariadnópolis. Era uma estrutura abandonada há mais de uma década, onde já havia funcionado uma escola municipal. A entrevistada 02 , que faz parte do setor de educação, também nos relatou o processo de ocupação do prédio que viria a ser a escola:

[...] no primeiro dia que nós ocupamos ali, foi um companheiro na frente com um facão fazendo aquela trilha pra gente passar e quando nós chegamos no saguão era só esterco, ali as vacas ficavam, dormiam, se coçavam, comiam; e nós chegamos e fizemos um café da manhã soltando rojão de frente pro "poderoso" (se referindo ao dono da ex-usina), e ele estava na casa esse dia (Entrevistada 02 - membro do coletivo de educação do MST- 13/06/2019).

Assim, após limpeza e reforma do prédio a escola passou a funcionar com a finalidade de receber cursos de formação (agricultura orgânica, tratorista e outros) e atividades 
educativas com as crianças, ou Ciranda Infantil. Ademais, no prédio, eram realizadas as reuniões e os eventos do MST.

Após a ocupação e reforma, a escola passou a receber diversos tipos de cursos enquanto o setor de educação do MST em Campo do Meio tomava as providências para que ela pudesse passar a funcionar em caráter oficial. Em 2016 as negociações com a Secretaria de Educação (SEE-MG) e a superintendência regional de ensino de Varginha-MG resultaram na aprovação de duas turmas de Educação de Jovens e Adultos (EJA) (na modalidade de ensino fundamental), no período noturno, e de uma turma de sexto ano do ensino regular, no período vespertino; o início das aulas se deu em setembro do mesmo ano. Para que a escola pudesse funcionar, a alternativa encontrada fora torná-la um anexo de uma escola da área urbana de Campo do Meio (Escola Estadual Doutor José Mesquita Netto).

Dos(as) quatro professores(as) que lecionavam na escola, apenas um possuía algum tipo de formação voltada para atender as realidades da Educação do Campo. O restante dos profissionais não possuía formação básica ou continuada voltada para essa realidade educacional, até mesmo porque eram professores da escola urbana; as disciplinas eram divididas em áreas do conhecimento (humanidades, matemática, ciências naturais e linguagens) e o currículo adotado (livros didáticos) seguia em grande parte os padrões urbanos. Esses fatores são considerados aqui enquanto empecilhos para a efetivação de um projeto de Educação Popular do/no Campo.

A organização da escola Eduardo Galeano apresentava algumas contradições, apesar de ser uma escola construída pelo MST, ela não pôde ser caracterizada em sua totalidade como uma escola pautada na Educação do Campo. Essa contradição reside no fato de que o currículo e a burocracia da escola seguiam a lógica urbana, devido à necessidade de se constituir enquanto um anexo de uma escola da cidade de Campo do Meio. Apesar disso, segundo os entrevistados, o movimento foi capaz de implementar algumas racionalidades e metodologias que se diferenciavam completamente da lógica trazida pelo modelo urbano:

[...] nós professores, com acompanhamento do setor de educação do MST, realizamos um processo educativo com elementos de nossa pedagogia. Por exemplo, a pedagogia do trabalho e da coletividade. Toda a escola foi reformada pelos nossos estudantes, que contribuíram na reforma do espaço, realizamos diversos mutirões para limpeza e manutenção do entorno da escola, o plantio de um pomar, as crianças plantaram uma horta, foi construído um parque infantil, durante as refeições os estudantes ajudavam a servir os colegas, inclusive muitos levavam alimentos que haviam plantados em suas lavouras para reforçar a alimentação escolar (Entrevistado 01 - educador na escola Eduardo Galeano- 25/05/2020).

As falas do entrevistado possibilitam um melhor entendimento sobre a maneira como a escola, as práticas e as metodologias utilizadas pelos educadores são condição e 
condicionante do processo de produção dos territórios camponeses. Neste sentido, a escola é vista e construída enquanto um espaço de resistência, de vivência e de promoção dos valores e modos de vida do campesinato.

Dessa forma, pode-se verificar a maneira como a produção do território camponês é condicionada pelos aspectos simbólicos que guiam sua luta. A criação de uma escola dentro de uma área que pertencia à ex-usina Ariadnópolis se configurou como um território de resistência. A escola pode ser entendida enquanto produto da organização territorial do campesinato e como produtora de novas intencionalidades e territorialidades para os sujeitos envolvidos no processo de ensino-aprendizagem:

[...] o MST vem trazendo com mais intencionalidade para suas escolas o debate da Agroecologia, entendida não apenas como a produção de alimentos saudáveis, livres de agrotóxicos, mas uma nova forma de vida e relação com a natureza [...]. Por isso reforçamos que a Agroecologia deve estar dentro dos currículos escolares e nas práticas da educação do campo (Entrevistado 01 - educador na escola Eduardo Galeano- 25/05/2020).

A Agroecologia, trabalhada enquanto conteúdo transversal, pode auxiliar os agricultores na delimitação de novas formas de produção e na consolidação de novos usos para seus territórios. Perguntado sobre o aprendizado na escola e sua importância para a produção em seus lotes, um dos camponeses disse que "Foi importante, porque a gente teve várias aulas né, tinha as aulas normais que os professores davam, além disso tiveram alguns cursos que a gente fez: como fazer adubo orgânico, fazer plantio com sementes crioulas" (Entrevistado 04 - educando da EJA - 23/08/2019). Neste sentido, escola se configurou enquanto um importante espaço para camponeses e camponesas compartilharem técnicas e conhecimentos produtivos, o que pode ser capaz de auxiliar na configuração de novas territorialidades por parte desses sujeitos. Portanto, a Educação do Campo possibilita a (re)organização das funcionalidades e racionalidades que permeiam a construção desses territórios.

Assim, a escola era parte fundamental do território do Quilombo Campo Grande no sentido de possibilitar a troca de experiências, de favorecer o compartilhamento de elementos simbólicos da cultura e da luta camponesa; era também um espaço público, coletivo, algo raro no campo brasileiro tão marcado pela propriedade privada e pela falta de espaços de encontro coletivo.

Um dos aspectos das disputas que envolvem a educação é justamente a visão de campo/campesinato que os modelos educacionais compartilham. Não basta para o campesinato que existam escolas em seus territórios, o modelo educacional precisa ser significante, ele deve favorecer a apropriação/produção do território para além de um viés produtivista (CAMACHO, 2014, 2019). Os conteúdos, as metodologias, as temporalidades 
das escolas camponesas pautam o campo e o território como espaço de reprodução dos costumes, do trabalho, dos modos de vida e dos costumes desses sujeitos. O território camponês não é apenas lócus da produção, ele é espaço de vida. Suas escolas seguem a mesma racionalidade.

Os entrevistados relataram que, desde o início do processo de criação da escola, a prefeitura de Campo do Meio tentou gerar dificuldades para a sua consolidação. Todos os entrevistados apontaram para a falta de respaldo da prefeitura quanto à disponibilização do transporte escolar como sendo um dos principais entraves enfrentados pelos alunos:

[...] ela (a prefeitura) fazia com que os ônibus não viessem trazer os alunos, olha, esses alunos que fizeram o fundamental, eles foram guerreiros. Porque tinha gente que andava 6 quilômetros para chegar na escola, porque não passava ônibus, noite chuvosa, barro, tudo isso (Entrevistada 02 - membro do coletivo de educação do MST-13/06/2019).

Além disso, os entrevistados que faziam parte do coletivo de educação informaram que muitas vezes não recebiam a merenda, sendo necessário que os próprios alunos e demais agricultores doassem alimentos para que pudesse haver a alimentação na escola: "[...] a merenda do estado não vinha, do município não vinha, então eles mesmos traziam. Um trazia cacho de banana, outro trazia abóbora, outro trazia mandioca, arroz, feijão e assim que foi feita a alimentação" (Entrevistada 03 - membro do coletivo de educação do MST- 23/08/2019).

Esses fatores mostram como a Educação no Campo segue sendo menosprezada pelos gestores públicos, e coube ao MST realizar atividades que são obrigação do estado e do município, como a merenda e o transporte escolar. Em 2019 foram destinados $R \$$ 43.036,00 para a execução do Programa Nacional de Transporte Escolar (PNATE) no município (FUNDO NACIONAL DE DESENVOLVIMENTO DA EDUCAÇÃO, 2019). Desta forma, a prefeitura contou com um valor considerável para a realização do transporte dos estudantes, o que não justifica a recorrente falta de ônibus escolares para o atendimento da comunidade do Quilombo Campo Grande.

O processo de fechamento das escolas e a opção pelo transporte dos alunos para a cidade é mais uma escolha política e eleitoral dos gestores do que, de fato, uma forma de economizar dinheiro. Exemplos do tratamento de questões educacionais por meio desta racionalidade neoliberal, pautada na redução de custos, também foram relatados em outras localidades e em outras pesquisas (CORREIA, 2018; MOLINA, 2015; PASTORIO, 2015; RODRIGUES, 2017; SILVA, 2016;).

É possível se identificar, no caso estudado e nas pesquisas citadas acima, como os gestores (denominação totalmente embutida de uma racionalidade neoliberal e corporativa) apresentam uma leitura hierárquica, pautando a superioridade dos modos de vida e dos 
espaços urbanos em relação aos modos de vida e aos espaços rurais. Neste sentido, o campo é tido como atrasado e a cidade como exemplo de modernidade. Esse discurso é permeado por intencionalidades que fazem com que haja ou o abandono escolar, ou a perda dos vínculos dos(as) educandos(as) com o campo e com seus territórios (MOLINA, 2015). Dessa forma, os educandos passam a ser envoltos pela realidade do espaço urbano e diversos são os impactos ocasionados em sua identidade cultural. Para Mônica Molina (2015, p. 389):

\begin{abstract}
Entre outras diversas graves consequências, constatou-se que este fechamento, com nucleação em escolas urbanas, tem provocado evasão precoce da juventude camponesa da escola, dadas as longas distâncias a percorrer e os longos períodos fora de casa; os riscos das estradas; e a precariedade dos transportes a eles disponibilizados. Nas pesquisas apresentadas sobre o fechamento das escolas das áreas de Reforma Agrária também se registra o abandono das turmas de Educação de Jovens e Adultos que ocorriam à noite, já que estes não têm condições de se locomoverem até as cidades para o prosseguimento das turmas. $O$ desenraizamento precoce das crianças e jovens reforça o círculo vicioso que continua produzindo jovens e adultos analfabetos no campo.
\end{abstract}

A necessidade de locomoção dos estudantes para estudar na cidade foi apontada durante as entrevistas como um dos fatores limitantes para os alunos(as) de EJA, os três estudantes entrevistados relataram que não iriam prosseguir com as aulas a partir do momento em que a escola foi fechada. Segundo eles:

Não iria, porque lá na cidade eu tenho um sentimento comigo que a gente é excluído, se chega lá com o pé sujo de barro eles falam: é da roça. E aí eu não acho isso certo. E o negócio ali, nós vamos do jeito que quiser, eu larguei do serviço, eu vou para aula e lá na rua não pode ir, porque a turma exclui, começando até dos professores (Entrevistado 04 - educando da EJA - 23/08/2019).

Impossível, tanto que quando fechou a escola e abriu vaga na cidade eu não consegui ir, a gente mora na roça, a gente trabalha, tem os compromissos. E, assim, o ônibus não passa quando chove, as vezes quando não chove também não passa, quando a gente está na colheita do café é muito difícil, porque o ônibus, quando ele passa, ele passa muito cedo, 18 horas ele já está passando, 18.20 ele já está passando e tem dia que a gente chega da roça é 18 horas. Não dá tempo de tomar banho e correr pro ponto do ônibus pra ir pra escola. A escola estando aqui não, você chega, toma um banho, é rapidinho, mesmo que você perdeu o ônibus, mas é perto né. Está praticamente dentro de casa a escola, e aí fica mais viável, é mais fácil. Ela abrindo, eu estou lá dentro dela de novo (Entrevistada 05 - educanda da EJA - 23/08/2019).

Seria praticamente impossível (estudar na cidade), por causa do transporte, né? Que nem agora mesmo, se nós quiséssemos voltar a estudar nós iríamos estudar lá (cidade) né? Eu já falei que não vou, porque eu sei que 
vai ficar discriminando as pessoas também, entendeu? Ainda mais idoso né, estudar com jovem (Entrevistada 06 - educanda da EJA - 23/08/2019).

Essas falas reforçam os apontamentos trazidos por Molina (2015), qual seja, o processo de fechamento das escolas do campo faz com que a superação do analfabetismo, especialmente para os estudantes da EJA, seja ainda mais difícil de se alcançar. Suas falas também destacam o preconceito que muitos camponeses seguem enfrentando ao estudarem na cidade. Neste sentido, o fechamento de escolas no meio rural pode apresentar diversos impactos para o modo de vida desses sujeitos, para a maneira como organizam e lutam por seus territórios, para os métodos escolhidos na produção de alimentos e até mesmo em seu vínculo com o campo.

Fatores como a falta de formação continuada para professores, de currículos e metodologias voltadas à realidade do campo e de uma organização educacional que leve em conta as temporalidades dos alunos trabalhadores (a exemplo da época da colheita do café) favorecem, de um lado, que os alunos abandonem seus estudos, e de outro, a perpetuação do histórico processo de desterritorialização e perda da cultura dos camponeses.

Em março de 2019 a escola popular Eduardo Galeano foi fechada, culminando, em agosto de 2020, na sua demolição por meio da ação da tropa de choque da Polícia Militar durante o processo de reintegração de posse realizado em parte das áreas da ex-usina. Os argumentos utilizados pelo governo estadual e municipal para o fechamento da escola eram pautados na redução de gastos, um exemplo da racionalidade neoliberal. Portanto, observou-se que os "motivos" para o fechamento da escola Eduardo Galeano são similares aos discursos de outros "gestores" públicos brasileiros.

O que outros pesquisadores vêm apontando em seus trabalhos (CORREIA, 2018; MOLINA, 2015; PASTORIO, 2015; RODRIGUES, 2017; SILVA, 2016) é que esse processo de fechamento de escolas do campo acompanhado da nucleação em escolas urbanas não está tão relacionado com a economia de dinheiro público, mas são decisões políticas.

Como já dito, a manutenção/consolidação dos territórios é, também, resultado de relações de poder sustentadas a partir de territórios imateriais. Os órgãos responsáveis pela educação (desde a escala municipal até a federal) são orientandos por racionalidades neoliberais, impactando nas políticas públicas educacionais e no grau de fechamento das escolas do campo (MOLINA, 2015). O entendimento do que vem a ser o campo brasileiro (espaço produtivo $x$ espaço de vida) e de qual deve ser a finalidade da educação (emancipadora $x$ empreendedora) se dá através de paradigmas, ou seja, de territórios imateriais que estão sendo disputados entre o agronegócio (e setores conservadores) e o campesinato, impactando diretamente no controle e na conformação de territórios materiais. 
O processo de reintegração de posse que levou à destruição da escola Eduardo Galeano ocorreu em meio a um contexto de crise sanitária (pandemia de COVID-19), o poder judiciário da região expulsou diversas famílias de suas casas e destruiu uma escola em favor de um grupo falido (CAPIA) que deve milhões de reais à união. Foi de uma violência simbólica enorme a destruição da escola, e esse representou mais um momento do conflito por terras que já dura 24 anos em Campo do Meio. Porém, lembramos que foi justamente pela falta de escolas no campo e pela violência sofrida pelos movimentos socioterritoriais que a luta por um projeto de Educação do Campo se iniciou.

\section{CONSIDERAÇÕES FINAIS}

O processo de fechamento das escolas do campo vem ocorrendo de maneira exacerbada no Brasil, de modo que não há uma correspondência clara entre esse processo e a diminuição da demanda por escolas. Os dados sobre a população rural brasileira não indicam uma redução tão acentuada que justifique o número de escolas fechadas (IBGE, 2010, 2015).

A revisão de bibliografia permitiu-nos chegar à conclusão de que este é mais um processo político do que uma busca por melhorias educacionais. Foi possível identificar que por detrás desse processo existe um discurso neoliberal de otimização da educação, de redução de custos e um entendimento de que as escolas e os modos de vida da cidade são qualitativamente superiores aos do campo.

Neste sentido, o processo de fechamento da escola popular Eduardo Galeano está inserido em um contexto de redução de verbas para a educação que atinge todo o Brasil e que não se resume somente às escolas do campo. O fenômeno de redução de "custos" educacionais é uma lógica que vem impactando escolas públicas urbanas, rurais e até mesmo universidades.

O processo atual de fechamento das escolas pode reproduzir as lutas dos movimentos socioterritoriais que foram responsáveis pelo início das reivindicações em prol do direito ao acesso à uma educação significativa em seus territórios.

O conflito não irá se encerrar enquanto não forem dadas condições para que esses camponeses possam viver com dignidade, plantar seus alimentos, ter uma casa para morar e uma escola para estudar, o que não nos parece ser privilégio.

Após a reintegração de posse de 14 de agosto de 2020, a direção do MST de Campo do Meio realizou uma campanha de arrecadação para a reconstrução da escola popular, conseguindo angariar a verba necessária para isso. Dessa vez a ideia é criar um centro de 
formação em Agroecologia. Esse processo comprova que a luta para entrar na terra ou para permanecer nela possui na educação um fator sine qua non.

\section{REFERÊNCIAS}

AMARAL, Jéssica Danielle Ferreira do. As relações de gênero nos acampamentos e assentamentos do município de Campo do Meio-MG. 2019. Monografia (Licenciatura em Geografia) - Instituto de Ciências da Natureza, Universidade Federal de Alfenas, Alfenas, MG, 2019.

ARROYO, Miguel González. Educação básica e os movimentos sociais. In: ARROYO, Miguel González; FERNANDES, Bernardo Mançano (org.). A educação básica e o movimento social do campo. Brasília, DF: Universidade de Brasília, 1999. v. 2, p. 65-86.

BRANDÃO, Carlos Rodrigues. Educação popular. São Paulo: Brasiliense, 1986.

CALDART, Roseli Salete. A escola do campo em movimento. Currículo sem Fronteiras, [S. I.], v. 3, n. 1, p. 60-81, jan./jun. 2003.

CALDART, Roseli Salete. Educação do campo: notas para uma análise de percurso. In: MOLINA, Mônica Castagna (org.). Educação do campo e pesquisa II: questões para reflexão. Brasília, DF: MDA/MEC, 2010. p. 103-126.

CALDART, Roseli Salete. Sobre a especificidade da educação do campo e os desafios do momento atual. [S. l: s. n.], 2015. Mimeografado.

CALDART, Roseli Salete; PEREIRA, Isabel Brasil; FRIGOTTO, Paulo Alentejano

Gaudêncio. Dicionário da educação do campo. Rio de Janeiro: Expressão Popular, 2012.

CAMACHO, Rodrigo Simão. O paradigma originário da educação do campo e a disputa de territórios materiais/imateriais com o agronegócio. Revista NERA, Presidente Prudente, SP, v. 22, n. 50, p. 64-90, 2019.

CAMACHO, Rodrigo Simão. Paradigmas em disputa na educação do Campo. 2014. Tese (Doutorado em Geografia) - Faculdade de Ciências e Tecnologia, Universidade Estadual Paulista "Júlio de Mesquita Filho", Presidente Prudente, SP, 2014.

CAMPOS, Janaina Francisca de Souza. Leituras dos territórios paradigmáticos da Geografia Agrária: análise dos grupos de pesquisa do estado de São Paulo. 2012. Tese (Doutorado em Geografia) - Faculdade de Ciências e Tecnologia, Universidade Estadual Paulista "Júlio de Mesquita Filho", Presidente Prudente, SP, 2012.

CARRILLO, Alfonso Torres. La educación popular: trayectoria y actualidad. Bogota: El Buho, 2011.

COCA, Estevan Leopoldo de Freitas; SANTOS, Leonardo Lencioni Mattos; SALVATERRA, José Roberto; FREITAS, Isabelle Medeiros de. Quando para impedir a reforma agrária vale até destruir escolas: a direita autoritária contra o acampamento Quilombo Campo Grande, em Campo do Meio-MG. Boletim DATALUTA, Presidente Prudente, SP, n. 151, p. 1-9, jul. 2020.

COLOGNESE, Silvio Antonio; MÉLO, José Luiz Bica de. A técnica de entrevista na pesquisa social. Cadernos de Sociologia, Porto Alegre, RS, v. 9, n. 4, p. 143-160, 1998.

CORREIA, Elis Santos. O fechamento das escolas do campo em Sergipe: territórios em disputa (2007-2015). 2018. Dissertação (Mestrado em Educação) - Universidade Federal de Sergipe, São Cristóvão, 2018. 
FERNANDES, Bernardo Mançano. Entrando nos territórios do Território. In: PAULINO, Eliane Tomiasi; FABRINI, João Edmilson (org.). Campesinato e territórios em disputa. São Paulo: Expressão Popular, 2008a. p. 273-302.

FERNANDES, Bernardo Mançano. Os campos da pesquisa em Educação do Campo: espaço e território como categorias essenciais. In: MOLINA, Mônica Castagna (org.). Educação do campo e pesquisa: questões para reflexão. Brasília: Ministério do Desenvolvimento Agrário, 2006. p. 27-40.

FERNANDES, Bernardo Mançano. Questão agrária: conflitualidade e desenvolvimento territorial. In: BUAINAIN, Antônio Márcio (org.). Luta pela terra, reforma agrária e gestão de conflitos no Brasil. Campinas: Unicamp, 2008b. p. 173-224.

FERNANDES, Bernardo Mançano. Sobre a tipologia de territórios. In: SAQUET, Marcos Aurelio; SPOSITO, Eliseu Savério (ed.). Territórios e territorialidades: teorias, processos e conflitos. São Paulo: Expressão Popular, 2009. p. 197-215.

FUNDO NACIONAL DE DESENVOLVIMENTO DA EDUCAÇÃO - FNDE. Liberação de recursos do Programa Nacional de Apoio ao Transporte do Escolar (PNATE) para a Prefeitura Municipal de Campo do Meio, 2019. Brasília, DF: FNDE, 2019. Disponível em: https://www.fnde.gov.br/sigefweb/index.php/liberacoes/resultadoentidade/ano/2019/municipio/311130/programa/D8/cnpj/18239582000129. Acesso em: 20 ago. 2020.

GOTTMANN, Jean. A evolução do conceito de território. Boletim Campineiro de Geografia, Campinas, SP, v. 2, n. 3, p. 523-545, 2012.

HAESBAERT, Rogério. Do corpo-território ao território-corpo (da terra): contribuições decoloniais. GEOgraphia (Niterói): revista do programa de pós-graduação em geografia, Niterói, RJ, v. 22, n. 48, p. 75-90, 2020.

IBGE. Censo agropecuário 2017: resultados preliminares. Rio de Janeiro: IBGE, 2018. Disponível em: https://biblioteca.ibge.gov.br/index.php/bibliotecacatalogo?view=detalhes\&id=73093. Acesso em: 20 jul. 2020.

IBGE. Censo Demográfico - 2010. População nos censos demográficos segundo as Grandes Regiões, as Unidades da Federação e a situação do domicílio - 1960/2010. Rio de Janeiro, RJ: IBGE, 2010. Disponível em: https://www.ibge.gov.br/estatisticas/sociais/populacao/9662-censo-demografico2010.html?=\&t=resultados. Acesso em: 30 mar. 2020.

IBGE. Pesquisa Nacional por Amostra de Domicílios. População residente, por situação do domicílio, sexo e idade, segundo a condição no domicílio e compartilhamento da responsabilidade pelo domicílio. Rio de Janeiro, RJ: IBGE, 2015. Disponível em: https://sidra.ibge.gov.br/tabela/1378\#resultado. Acesso em: 9 nov. 2020.

INSTITUTO NACIONAL DE ESTUDOS E PESQUISAS EDUCACIONAIS ANÍSIO TEIXEIRA. Sinopse estatística da Educação Básica 2010. Brasília: Inep, 2011. Disponível em: http://portal.inep.gov.br/web/guest/sinopses-estatisticas-da-educacao-basica. Acesso em: 18 jun. 2020.

INSTITUTO NACIONAL DE ESTUDOS E PESQUISAS EDUCACIONAIS ANÍSIO TEIXEIRA. Sinopse estatística da Educação Básica 2019. Brasília: Inep, 2020. Disponível em: http://portal.inep.gov.br/web/guest/sinopses-estatisticas-da-educacao-basica. Acesso em: 18 jun. 2020.

LUCAS, Kelson Serafini; VALE, Ana Rute do. Assentamento Primeiro do Sul: passado de luta, presente de resistência e futuro de incertezas. Geografia, Ensino \& Pesquisa, Santa Maria, RS, v. 18, n. 1, p. 7-22, 2014. 
MOLINA, Mônica Castagna. A educação do campo e o enfrentamento das tendências das atuais políticas públicas. Educação em Perspectiva, Viçosa, MG, v. 6, n. 2, p. 378-400, jul./dez. 2015.

MOREIRA, Dorcelina Aparecida. Das "escolinhas de favores" à "escola de direito": a educação no/do campo no município de Goiás. Revista NERA, Presidente Prudente, SP, ano 21, n. 42, p. 153-176, maio/ago. 2018.

PASTORIO, Eduardo. Nucleação das escolas do campo: o caso do município de São Gabriel/RS. 2015. Dissertação (Mestrado em Geografia) - Centro de Ciências Naturais e Exatas, Programa de Pós-Graduação em Geografia e Geociências, Universidade Federal de Santa Maria, Santa Maria, RS, 2015.

RAFFESTIN, Claude. Por uma geografia do poder. São Paulo: Ática, 1993.

REIS, Herique Heber dos Santos; SOBREIRO FILHO, José; RABELO, Ederlane Vale. Território, movimentos socioterritoriais e Educação do Campo. Caminhos de Geografia, Uberlândia, MG, v. 20, n. 69, p. 253-265, 2019.

RODRIGUES, Maria Diva da Silva. Política de nucleação de escolas: uma violação de direitos e a negação da cultura e da educação escolar quilombola. 2017. Dissertação (Mestrado em Desenvolvimento Sustentável junto a Povos e Terras Tradicionais) Universidade de Brasília, Brasília, DF, 2017.

SANTOS, Ailton Dias dos. Metodologias participativas: caminhos para o fortalecimento de espaços públicos socioambientais. São Paulo: Petrópolis, 2005.

SANTOS, Fernando Henrique Tisque dos; SOUZA, Maria Antônia de. Educação do Campo e MST. Revista Olhar de Professor, Ponta Grossa, PR, v. 10, n. 2, p. 213-224, 2007.

SILVA, Edilma José da. A territorialização da política de nucleação e o fechamento de escolas no campo em União dos Palmares/AL (2005-2015). 2016. Dissertação (Mestrado em Geografia) - Universidade Federal de Sergipe, São Cristóvão, 2016.

SOBREIRO FILHO, José. As lutas territoriais da memória contra o esquecimento. CampoTerritório: Revista de Geografia Agrária, Uberlândia, MG, v. 15, n. 35, p. 172-201, abr. 2020.

SOBREIRO FILHO, José. Contribuição à construção de uma teoria geográfica sobre movimentos socioespaciais e contentious politics: produção. Tese (Doutorado em Geografia) - Universidade Estadual Paulista Júlio de Mesquita Filho, Presidente Prudente, SP, 2016.

STÉDILE, João Pedro; FERNANDES, Bernardo Mançano. Brava gente: a trajetória do MST e a luta pela terra no Brasil. São Paulo: Expressão Popular, 1999.

STRECK, Danilo Romeu. Metodologias participativas de pesquisa e educação popular: reflexões sobre critérios de qualidade. Interface: comunicação, saúde, educação, Botucatu, SP, v. 20, p. 537-547, 2016.

TAFFAREL, Celi Zulke; MUNARIM, Antonio. Pátria educadora e fechamento de escolas do campo: o crime continua. Revista Pedagógica, Chapecó, SC, v. 17, n. 35, p. 41-51, maio/ago. 2015.

VALE, Ana Rute do; AMARAL, Jéssica Danielle Ferreira do; SANTOS, Leonardo Lencioni Mattos; PLATINI JÚNIOR, Paulo Roberto; ANDRADE, Rodrigo Santos de. Reprodução social e agroecologia nos Assentamentos Primeiro do Sul e Nova Conquista II de Campo do Meio - MG. Revista Retratos de Assentamentos, Araraquara, SP, v. 22, n. 2, p. 215-240, 2019.

Recebido: abril de 2021. Aceito: julho de 2021. 